\title{
Matemática, leitura e aprendizagem
}

Justiani Hollas

justiani@unochapeco.edu.br

Clairiane Teresinha Hahn

clairiane@unochapeco.edu.br

Rosemari Ferrari Andreis

rosemari@unochapeco.edu.br

\begin{abstract}
Resumo
O ensino de Matemática, aliado à Literatura, parte do pressuposto de que é possível romper a visão cristalizada, frequentemente verificada na prática pedagógica tradicional. Neste âmbito, o presente trabalho tem como objetivo analisar as possibilidades de utilização da Literatura no contexto escolar, aliada a prática pedagógica dos educadores para o ensino e aprendizagem da Matemática, contribuindo, assim, com o desenvolvimento do hábito de leitura de estudantes do Ensino Fundamental. Com base em um estudo bibliográfico, busca-se explorar a viabilidade da utilização da Literatura para o ensino de Matemática como uma alternativa que merece ser inserida no meio educacional. Além disso, desenvolveu-se o estudo de ações pedagógicas, embasadas em concepções da autora Smole e em criações das próprias pesquisadoras, tendo como foco a sala de aula, mais especificamente, turmas de $5^{\text {a }}$ série do Ensino Fundamental. Por meio da revisão de perspectivas teóricas e da aplicação de atividades elaboradas para estudantes das séries iniciais desse nível de ensino, ressaltou-se a relevância do tema, cujo resultado principal aponta para a viabilidade da utilização da Literatura no processo de ensino eaprendizagem de Matemática como método dinâmico e eficiente para o enfoque à interdisciplinaridade dos conteúdos a serem explorados em ambiente escolar. Evidenciam-se, também, os resultados satisfatórios de aprendizagem e a ampla receptividade dos estudantes para com o método proposto.
\end{abstract}

Palavras-chave: Matemática. Literatura. Ensino.

\begin{abstract}
The Mathematics teaching allied to Literature comes from the idea that is possible to break the crystallized vision, mostly verified into the tradicional pedagogical practice. In this scope, we starts from the goal to analyse the possibilities of using Literature in the scholar context, allied to the pedagogical practice of teachers in order to teach and learning Mathematics, contributing with the development of lecture habit among fundamental students. Based on a bibliographical study, has been analysed the possibility of using Literature to the Math teaching as an alternative what deserves to be inserted in the educational field. Besides, it has been developed also the study of pedagogical actions, based on conceptions of the author Smole and on creations of the own researchers, focusing the classroom, more especifically, groups of the 5th grade of elementary school. Through the review of theorical perspectives and the application of activities developed to this level of inicial series students of teaching, was highlighted the theme relevance, whose principal effect leads to the possibility of using Literature in the process of teaching-learning Mathematics as a dynamical method and efficient to the focus into
\end{abstract}


interdisciplinarity of contents to be explored at the scholar environment. Are evident also, the good results of learning and the large receptivity of the students with the proposed method.

Keywords: Math. Literature. Teaching.

\section{Introdução}

A convenção estabelecida é que estudantes leiam livros didáticos e literários durante o horário de aula ou para realizar as tarefas extraclasse, sendo que muitas vezes a leitura é compreendida como algo obrigatório e relacionado apenas as disciplinas da área de Letras, principalmente Língua Portuguesa. Entende-se, todavia, que trabalhá-la como ação que permite uma oportunidade de engrandecimento intelectual, sadia e prazerosa, traz benefícios e aspectos positivos em diversas áreas do conhecimento, até mesmo (e, por que não dizer, infalivelmente) para a Matemática, haja vista que, para o desenvolvimento do raciocínio lógico, algébrico e abstrato, é fundamental que seja desperta nos estudantes a capacidade de interpretação.

A utilização da Literatura nas aulas de Matemática contribui para a desmistificação de paradigmas pré-estabelecidos na sociedade há várias décadas, quando aponta a Matemática idealizada como uma disciplina abstrata, difícil e inacessível.

As relações entre a Literatura e a Matemática, se corretamente articuladas, podem ser compreendidas como possibilidades para vincular o contexto cultural e social às aulas, fazendo uma ponte entre o concreto e o abstrato, aspecto fundamental para a contextualização de conteúdos matemáticos, podendo, inclusive, proporcionar ao estudante a capacidade de análise crítica sobre o mundo que o cerca, além de desenvolver a competência de argumentação, expressão e sistematização.

A utilização da Literatura, vista sob uma perspectiva matemática, é uma forma diferente e prazerosa de aprender, que exige empenho e atenção por parte de educadores e estudantes, mas que também gera motivação para que ambos possam buscar novos conhecimentos, bem como mostrar que é possível aprender e compreender a Matemática sem "monotonia", como muitos assim concebem seu estudo ante as clássicas práticas escolares.

A busca por assuntos atuais presentes no cotidiano e a necessidade de instigar os estudantes a ver a Matemática como algo construtivo e contextualizado com situações imaginárias e reais e, principalmente, tornar o ensino menos tradicional e enfadonho, foram os principais fatores 
motivadores do presente estudo, entendendo que se concebe a Literatura e a Matemática como duas áreas fundamentais para a formação humana, social e intelectual.

Nessa perspectiva, foi intuito deste trabalho propor atividades lúdicas e dinâmicas ao educador da disciplina de Matemática, para que este detenha maiores condições de desenvolver seu trabalho em sala de aula, amparado pela possibilidade de utilização de obras literárias como "pano de fundo" para a inserção de especificidades matemáticas que, se não trabalhadas de maneira dinâmica e contextualizada, correm o risco de serem consideradas, sob o olhar discente, ingênua e, erroneamente, como "meras invenções desnecessárias da humanidade".

A Literatura, pelo fato de sempre trazer novas perspectivas, visões de mundo contextualizadas e por ser caracterizada como uma arte, está em constante transformação/inovação, representando diversas percepções da realidade. Quem possui o hábito de leitura, por consequência, escreve bem, sabe expressar-se com facilidade e de maneira correta, consegue interpretar todo tipo de situação textual, possui argumentos críticos, entre outros aspectos positivos que são utilizados na Matemática.

Por meio do estudo teórico, procurou-se intensificar a observação sobre o tema proposto pela presente pesquisa, tendo como foco a Matemática e Literatura, tornando-se possível discorrer sobre os aspectos positivos da utilização da Literatura nas aulas de Matemática, bem como ponderar sobre alguns dos desafios do educador e dos cuidados que devem ser analisados quando se busca a inovação, especialmente com a finalidade de empregar os livros literários na construção significativa de conceitos matemáticos.

Posteriormente, ao longo do estudo propositivo-experimental, relatar-se-á uma série de atividades desenvolvidas e aplicadas em turmas de $5^{\text {a }}$ série, atual $6^{\circ}$ ano, do Ensino Fundamental, por meio de atividades que dinamizam as ações desenvolvidas pelo educador, explorando a Matemática a partir da Literatura e propondo como o profissional educacional dessa área pode contribuir com a formação do hábito da leitura nos estudantes do Ensino Fundamental. A obra literária utilizada para elaboração das atividades envolvidas no estudo foi o livro intitulado As Três Partes, de autoria de Edson Luiz Kosminski (Editora Ática).

A seguir, será abordada a metodologia utilizada na realização da pesquisa, também os materiais empregados em cada categoria de estudo. Por fim, são apresentados os resultados e discutidas as conclusões, pelas das quais busca-se sintetizar o conhecimento gerado pela pesquisa, discorrendo sobre a validade e importância dos estudos concretizados. 


\section{Materiais e métodos}

O presente artigo é resultado de um estudo baseado em procedimento metodológico teórico e propositivo, desenvolvido, primordialmente, pela pesquisa bibliográfica, realizada por meio do estudo de livros, publicações periódicas, artigos científicos, revistas da atualidade e obras literárias, entre outros materiais. A documentação escrita, realizada a partir da coleta de dados e posterior análise descritiva, propiciou o embasamento para o desenvolvimento de proposições de ações pedagógicas.

Portanto, com o intuito de aplicar os dados obtidos com a pesquisa documental, e promover uma análise sobre diversas atividades envolvendo a Literatura no estudo da Matemática, foi elaborada e aplicada uma oficina com o tema geometria.

O público alvo englobou a $5^{\text {a }}$ série, atual $6^{\circ}$ ano, do Ensino Fundamental, sendo uma turma da Escola de Educação Básica José Marcolino Eckert, de Pinhalzinho - SC, e uma da Escola Estadual de Ensino Médio Maria Dulcina, de Nonoai - RS, envolvendo, aproximadamente, um total de 60 (sessenta) estudantes com a devida autorização das direções das escolas e dos professores de Matemática titulares das turmas. A realidade cultural e econômica de cada região apresenta diferenças fundamentais para a análise de aspectos positivos e também das dificuldades e adaptações que cada realidade requer. A escolha das escolas citadas deveu-se ao fato de serem conveniadas com a Unochapecó, e campo de estágio das pesquisadoras.

As etapas que compuseram a aplicação das oficinas foram:

i) apresentação da história aos estudantes, por meio de recursos pedagógicos diversificados;

ii) discussão, contextualização da história, e exploração de conteúdos matemáticos a ela relacionado;

iii) produção literária e matemática pelos estudantes, conforme atividades trabalhadas durante as oficinas.

iv) análise (pelas pesquisadoras) das atividades desenvolvidas.

Para o desenvolvimento das atividades, utilizou-se como objeto central do estudo proposto o livro de literatura infantil As Três Partes, fazendo-se utilitário o recurso audiovisual data show para a apresentação e leitura coletiva da referida história. Também fez-se uso de instrumentos didáticos presentes no cotidiano escolar, como: cola, papel colorido, tesoura e lápis de diversas cores, além de outros materiais comumente utilizados para atividades 
escolares artísticas ou recreativas, como: isopor, papel crepom e cola colorida (alguns destes fornecidos pelas pesquisadoras às turmas). Ministrou-se esta oficina numa perspectiva que abrange a ludicidade e a exploração de recursos diversos.

\section{Aportes teóricos e análise da experiência}

A demanda pela leitura, bem como uma boa comunicação escrita e oral, são exigências da sociedade há algumas décadas. Decorrente dessa necessidade, hoje as escolas precisam possibilitar a formação para a leitura, vinculada ao contexto social do estudante, para sua efetivação num saber agir, organizar, criticar e apropriar-se do conhecimento. Além disso, é por meio da leitura que o sujeito leitor conhece a evolução, a cultura e a história de diversos povos nos mais variados períodos, refletindo na capacidade de apropriar-se da realidade e de produzir/difundir seu próprio entendimento acerca desta.

Além de contribuir para a ampliação do vocabulário, a leitura possibilita que os estudantes possam adentrar em mundos diferentes, (re)significando saberes e sentindo-se despertos para a liberdade imaginária que os permitirá desvendar mistérios, elaborar questionamentos e, finalmente, buscar as explicações que possam sanar tais inquietações.

Para Smole et al. (1999, p. 09): “[...] a literatura infantil não apenas pode ser um modo desafiante e lúdico para as crianças pensarem sobre algumas noções matemáticas, mas também propiciar um contexto significativo para a formulação e a resolução de problemas". Embasando-se nas infinitas situações e personagens que surgem no decorrer das histórias, torna-se muito mais fácil para educador e educando associar conteúdos matemáticos com situações corriqueiras, bem como elaborar uma sequência lógica de argumentos que possam ser favoráveis para a busca das soluções desejadas.

Smole et. al. ressalta ainda que:

Se um determinado material, usado em aulas de matemática, estiver adequado às necessidades do desenvolvimento da criança, as situações-problema colocadas a ela enquanto manipula esse material, fazem com que haja interesse e sentimento de desafio na busca por diferentes soluções aos problemas propostos. (1999, p. 16)

Diante de tamanhas contribuições que o campo literário tende a ofertar para o bom rendimento do trabalho do profissional da educação, em áreas diversas, passa-se a tratar a possibilidade de utilização da Literatura como alternativa viável e convencional para o ensino de Matemática. 
O uso da literatura infantil, em conexão com o trabalho de resolução de problemas, permite aos alunos e professores utilizarem e valorizarem, naturalmente, diferentes recursos na busca por uma solução, tais como, desenho, oralidade, dramatização, tentativa e erro, elaboração de jogos (trilha, dominó, memória,...) confecção de varal com a sequência das cenas da história, atividades classificatórias envolvendo tamanho, peso, altura dos animais que são personagens da história. (SALVADOR; SILVA; ZINI, 2007, p. 01).

Esse recurso metodológico leva os estudantes a desenvolver capacidades de raciocínio e representação que podem ser utilizadas tanto no cotidiano escolar, quanto em situações corriqueiras da vida deles, cada vez mais complexas. As atividades em grupo também são produtivas desde os anos iniciais, pois desenvolvem a comunicação. Outro tipo de abordagem dos conteúdos é a resolução de problemas com desenhos. Logo, uma das alternativas é utilizar a Literatura e suas ilustrações como recurso exploratório dos conteúdos matemáticos.

São as situações-problema desencadeadas pelos personagens que estimulam a interpretação, desenvolvem as estruturas mentais e a capacidade de solucionar problemas, instigando os estudantes a visualizar o melhor caminho para alcançar objetivos (respostas). No entanto, conforme ressalta Salvador et al. (2007), não se pretende que a literatura fique subjugada à exploração matemática e científica, uma vez que sabemos ser o encanto e o prazer por ler as histórias a primeira e principal função da literatura na escola, em qualquer idade.

Face a todos os detalhamentos educacionais a serem observados, quando do emprego de obras literárias como pano de fundo, para a exploração matemática que se pretende realizar, configura-se a capacitação do educador como um dos mais importantes e louváveis fatores a serem considerados para o rendimento satisfatório das atividades propostas aos estudantes.

Literatura aliada a Matemática, por se tratar de uma concepção atual de ensino, necessita da formação continuada para que os educadores saibam lidar com essa relação interdisciplinar. Além disso, faz-se necessário, também, que o educador possua uma mentalidade aberta para discussões, críticas e, sem medo de arriscar, pois o trabalho pode ser recebido pela comunidade escolar como algo maléfico, que possa prejudicar e atrasar o ensino da Matemática em si, sob os moldes das concepções mais tradicionais de ensino.

Utilizar a Literatura como recurso no processo de ensino aprendizagem de Matemática tende a representar, além de um método inovador e, por que não dizer, audacioso, também uma prerrogativa para que sejam incentivadas as práticas de leitura em meio à comunidade escolar.

A expressão de conceitos matemáticos através da escrita permite ao educador uma análise sobre a assimilação e incompreensões dos estudantes. Assim, a história induz a busca de 
relações entre a língua materna e a linguagem formal que, no caso da Matemática, pode ser realizada por meio de gráficos, tabelas, textos, fórmulas, entre outros, explorando duas áreas do conhecimento ao mesmo tempo.

Contudo, de nada adianta aplicar a Literatura nas aulas se o educador não tomar alguns cuidados, como: conhecer a história antes de apresentá-la à classe e saber as possibilidades de trabalho que ela permite; explorar a Matemática durante a história, porém, sem romper seu sentido; conhecer o gosto dos estudantes em relação às histórias; e, por fim, explorar o livro com calma e emoção, de maneira que crie expectativas.

Outra característica importante que o educador deve possuir é o gosto pela leitura, transpassando o prazer e a importância de ler para a vida dos estudantes. Como afirma Smole et al. (2007, p. 9), “a impressão fundamental da história não deve ser distorcida por uma ênfase indevida em um aspecto matemático".

Promover uma aula inovadora, com atividades interessantes e que despertem a curiosidade dos estudantes é imprescindível para o sucesso do educador e do estudante em sala de aula. Cabe destacar, no entanto, que a falta de tempo e a necessidade de cumprimento de um rol de conteúdos ao longo de um ano letivo representam alguns dos empecilhos para a atuação desse profissional.

\begin{abstract}
O que também se observa em termos escolares é que muitas vezes os conteúdos matemáticos são tratados isoladamente e são apresentados e exauridos num único momento. Quando acontece de serem retomados (geralmente num mesmo nível de aprofundamento, apoiando-se nos mesmos recursos), é apenas com a perspectiva de utilizá-los como ferramentas para a aprendizagem de novas noções. De modo geral, parece não se levar em conta que, para o aluno consolidar e ampliar um conceito, é fundamental que ele o veja em novas extensões, representações ou conexões com outros conceitos. (BRASIL, 1997, p. 22)
\end{abstract}

A apropriação do conhecimento é o momento vital da educação, que implica um processo de transformação, onde o sujeito recebe as informações, de certa maneira brutas, e as transforma/constrói num processo de assimilação desse conhecimento. Por isso, é fundamental que os estudantes participem ativamente das aulas e que, por fim, sejam capazes de expor e aplicar o que aprenderam em diversas situações.

Com o intuito de verificar a viabilidade da utilização da Literatura como alicerce para o desenvolver de conteúdos matemáticos, elaborou-se a oficina intitulada Brincando $e$ aprendendo Matemática com As Três Partes. 
Ao utilizar a obra literária As Três Partes, buscou-se relacionar conteúdos abordados em sala de aula com práticas do cotidiano dos estudantes, sendo este fator fundamental para que os educandos desenvolvam a capacidade de realizar a correlação entre as informações e suas aplicabilidades. Constituindo-se como parte integrante dos temas previstos nos Parâmetros Curriculares Nacionais (PCN's), bem como comportando uma grande gama de conceitos que podem ser trabalhados de diversas formas e contextualizados, a geometria é tida como foco do estudo ora proposto.

Buscou-se, sobretudo, associar o estudo de geometria ao recurso literário, incentivando o gosto pela leitura e promovendo a contextualização do conteúdo, abordando-o com situações práticas vivenciadas pelos estudantes em seu cotidiano, instigando seu pensamento reflexivo e a criatividade, especialmente, a partir da manipulação de figuras e introduzindo conceitos geométricos.

\footnotetext{
O livro conta a história de uma casa que resolve ser outras coisas. Para tanto, ela se divide em três partes que, a partir daí, vão montando novas formas e saem pelo mundo para conhecê-lo, vivendo diferentes experiências e aventuras. A leitura deste livro propicia um trabalho com formas geométricas, área, perímetro, ângulo, simetria de reflexão e de rotação. (SMOLE et. al., 2007, p. 26)
}

Para a elaboração das atividades relativas a história As Três Partes, utilizou-se como instrumento de consulta e embasamento, algumas das sugestões apresentadas por Smole et. al. (2007, p. 26-40), assim como outras atividades criadas pelas pesquisadoras durante a preparação da oficina.

Muito embora o livro seja indicado para elaboração/realização de atividades para pré-escola e para anos iniciais do Ensino Fundamental, verificou-se que nas realidades locais observadas, devido a uma série de fatores que acabam por evidenciar a decadência do setor educacional no cenário nacional, os estudantes de quinta série, que já deveriam ter formados certos conceitos geométricos, não os tem. As dificuldades de reconhecimento das formas geométricas apresentadas pela história e, sobretudo, as dificuldades de execução da leitura, contribuíram com a elevação dos níveis de dificuldades para compreensão de conceitos como perímetros e áreas.

O primeiro momento da oficina elaborada teve como foco despertar o hábito de leitura e promover a diferenciação de figuras geométricas planas. Para início, encaminharam-se as turmas para a sala reservada para o desenvolvimento de atividades com uso de data show, 
permitindo a leitura da história e socialização das ideias centrais do texto. Os estudantes participaram fazendo a leitura de trechos da história infantil.

Por se tratar de uma atividade diferente e inovadora, se comparada com os métodos tradicionais de ensino de Matemática, o momento oportunizou ampla participação dos estudantes, possibilitando-lhes prever e palpitar sobre a sequência a qual a história conduzia. A formulação de hipóteses e o anseio em expressar suas ideias os motivaram a indagar e refletir sobre as questões matemáticas apresentadas no decorrer da apresentação. Muito embora a participação e interatividade tenham sido fatores positivamente avaliados, em contrapartida, existem ressalvas quanto as dificuldades de concentração que muitos estudantes apresentaram, de interpretação e falhas verbais de reprodução da leitura.

As discussões surgiam ao passo em que iam sendo feitos questionamentos às turmas, a fim de verificar o conhecimento prévio sobre noções de nomes de figuras geométricas, número de ângulos (cantos) e lados das figuras representadas no livro. Para tanto, procurou-se contextualizar as figuras com as formas presentes na sala de aula e nas principais atividades cotidianas dos estudantes.

Neste segundo momento da aula, cada estudante recebeu reproduzido em E.V.A. o desenho da casa que apareceu na história. Os estudantes foram instigados a analisar e pensar nas alternativas de realizar três cortes para "desmontar" a casinha e transformá-la em três partes, sendo que muitas ideias foram expostas. Após ouvir algumas ideias, propôs-se o recorte de um trapézio e dois triângulos, conforme figura indicada na sequência da história.

Posteriormente, procurou-se explorar conceitos como o número de ângulos (cantos) e número de lados, bem como se reforçaram as diferenças e semelhanças de cada figura, como por exemplo, o quadrado, que possui 4 (quatro) lados iguais e 4 (quatro) ângulos. Por observar-se que as turmas já conheciam o conceito de ângulo, introduziu-se o conceito de ângulo reto e a diferença entre o triângulo retângulo e as demais classificações dessa forma geométrica.

Procurou-se abordar conceitos geométricos de forma simplificada sobre as três figuras representadas no livro, fundamentando-se em alguns dos seguintes questionamentos aos estudantes:

- Vocês (estudantes) já conheciam essas figuras?

- Alguém sabe o nome delas?

- Quantos lados e "cantos” elas tem? 
- Vocês percebem na sala e no seu dia a dia formas parecidas com elas?

Em seguida, realizou-se uma análise sobre os exemplos de formas geométricas encontradas no dia a dia. Alguns estudantes expuseram suas sugestões sobre as figuras geométricas presentes no material escolar e no ambiente da sala de aula. Dentre os exemplos, foram citados materiais como: livro, caderno, borracha, régua, mesa, piso da sala, as paredes etc., denotando a correta relação entre o conteúdo então abordado e sua própria realidade.

As colocações dos estudantes e as explicações das pesquisadoras iam sendo expostas no quadro, para fins de maior fixação do conteúdo abordado e assimilação com outras experiências por eles já vivenciadas. Depois de nomeadas as figuras e explicados os principais tópicos a elas correspondentes, distribuiu-se aos estudantes, em papel A4, as principais figuras geométricas com suas respectivas denominações, servindo como material para posteriores consultas.

Confirmando-se o que expõe Smole et. al., em termos gerais, entende-se que:

estabelecer conexão em matemática pode implicar em:

a) relacionar as ideias matemáticas à realidade, de forma a deixar clara e explícita sua participação, presença e utilização nos vários campos da atuação humana, valorizando, assim, o uso social e cultural da matemática;

b) relacionar as ideias matemáticas com as demais disciplinas ou temas de outras disciplinas;

c) reconhecer a relação entre diferentes tópicos da matemática, relacionando várias representações de conceitos ou procedimentos umas com as outras;

d) explorar e descrever resultados, usando modelos ou representações gráficas, numéricas, físicas e verbais. (2007, p. 03)

Avaliou-se a participação dos estudantes como expressiva, possibilitando concluir que conseguiram construir uma relação entre os conceitos geométricos utilizados durante a aula e as formas presentes no próprio ambiente escolar. Dessa maneira, substituindo a mecanização da utilização das regras matemáticas, que impedem uma verdadeira compreensão das ideias e dos significados simbólicos muito presentes nas aulas de Matemática.

De posse das 03 (três) figuras recortadas durante a realização da atividade anterior, foi proposto que cada estudante criasse uma montagem de qualquer personagem, explorando o máximo de sua criatividade. $\mathrm{Na}$ atividade, utilizaram-se os movimentos de rotação e translação das figuras. Ao formar um personagem qualquer, que tivesse ou não aparecido na história, os estudantes colaram a figura em papel A4, distribuída pelas pesquisadoras. 
$\mathrm{Na}$ montagem da figura, observou-se que os estudantes utilizaram vasta criatividade, momento no qual criaram objetos, animais e até pessoas, por meio da movimentação e posterior colagem das três figuras geométricas (dois triângulos retângulos e um trapézio). Além de colar a figura, os estudantes foram estimulados a colorir e enfeitar o trabalho, logo, a atividade tornou-se completa com a criação de um cenário para a figura, a partir da pintura com materiais como canetas e lápis coloridos. Para a realização dessa atividade, organizou-se a sala de maneira que os estudantes realizassem os trabalhos sentados em duplas ou em grupos com quatro estudantes, medida esta considerada como fundamental para a socialização de ideias e materiais didáticos.

Posteriormente, propôs-se aos estudantes a atividade de dissertação de um pequeno texto sobre o personagem criado, produção esta desenvolvida em outra folha A4. Durante o desenvolvimento do texto, houve a sugestão para que adotassem critérios como forma, utilidade, características, semelhanças com figuras ou objetos do cotidiano, além de poder detalhar a montagem, entre outros aspectos que cada um observasse e considerasse conveniente escrever a respeito da figura.

Por fim, cada estudante fez uma apresentação oral para a turma, expondo o personagem e fazendo a leitura do texto. Portanto, tal atividade desempenhou importante contribuição na construção significativa de saberes, buscando a efetividade de objetivos como despertar capacidades de comunicação oral e escrita, bem como tornar a aula mais divertida e promover a troca de ideias e o compartilhamento das informações, que surgiram com o desenvolvimento das atividades. Para a execução dessa atividade, ambas as turmas participaram ativamente e colaboraram de maneira exemplar com o andamento dos trabalhos.

Considera-se, que além de descontrair a aula, mexendo com o mundo imaginário dos estudantes e despertando a criatividade deles, a atividade de criação do personagem e história foi significativa para elencar o conteúdo à realidade, ou seja, aos aprendizados, fatos e objetos que os cercam. Os personagens criados a partir das "três partes" foram:

a) animais como papagaio, cachorro, gato, peixe, morcego, coelho e borboleta, com seus respectivos cenários e histórias variadas, contendo aspectos imaginários ou reais;

b) flores de diversos formatos, enfeitadas por jardins e bosques, ligadas aos relatos produzidos e aos acontecimentos imaginários. 
c) personagens como o índio e construções como a barragem, que fazem parte do contexto social em que a instituição escolar de Nonoai está inserida, remetendo a exposição das particularidades de sua própria história e identidade cultural;

d) pinheiros de Natal, com formatos diferentes, relacionados à data comemorativa, por meio dos quais se expuseram sonhos sinceros de Natais felizes, tristes e expectativas para o futuro;

e) barcos, também com diversos formatos, navegando sobre cenários divertidos como mares, rios e lagos, e até barcos voadores, despertando o caráter imaginário;

f) objetos diversos como o peão, remetendo às brincadeiras desenvolvidas desde a infância, momentos relembrados e expressos com saudade;

g) avô, remetendo o estudante a escrever sobre aspectos afetivos e a importância da família.

A criatividade dos estudantes superou as expectativas. Em posterior leitura, notou-se que existem muitas dificuldades na escrita e na composição de frases. Em muitos textos é possível verificar a utilização inadequada de diversas letras, considerando que a dificuldade de concentração durante a realização da atividade e a falta do hábito de leitura estão entre os principais fatores que conduzem a esses equívocos.

\section{Considerações finais}

Diante dos dados apresentados e discutidos, cabe destacar que o ato de ler desperta aptidões indispensáveis em todos os momentos da formação escolar e, também, no decorrer das mais variadas atividades desenvolvidas no cotidiano. Por isso, é amplamente discutida a concepção de que se deve trabalhar a formação dos estudantes para que sejam leitores assíduos, permitindo que desenvolvam tal ato com prazer, facilidade e sabedoria, não somente em atividades da disciplina de Língua Portuguesa, como geralmente pode-se notar, mas em todas as disciplinas, ressaltando o desafio e a importância de sua iminente utilização na disciplina de Matemática.

Ao analisar as habilidades que o sujeito leitor atinge no campo matemático, compreendeu-se que são desenvolvidas capacidades de arguição, interpretação e análise, usualmente atreladas na resolução de situações problemas que requer desenvoltura quanto à interpretação e utilização dos dados apresentados. A leitura contínua também influencia para desenvolver a 
concentração, proporcionando, assim, maior introspecção de informações absorvidas, a partir de explanações orais ou escritas. Destaca-se, por fim, que o sujeito leitor sabe expressar-se, seja de maneira escrita ou falada. Sendo assim, promove a organização de seus pensamentos, tornando o processo de aprendizagem mais organizado e sistematizado.

De antemão encontraram-se obstáculos comumente verificados no cotidiano escolar, dentre os quais se pode citar: o elevado número de estudantes na composição das turmas; a indisponibilidade de grande variedade de recursos e materiais pedagógicos que pudessem enriquecer a prática docente; atitudes comportamentais indisciplinares, demonstradas por alguns dos estudantes; desinteresse pelos conteúdos matemáticos; e falta do hábito de leitura, fator este que restou por influenciar negativamente para a compreensão e agilidade na resolução das atividades propostas.

Em contrapartida, apontam-se como fatores favoráveis das turmas participantes da presente pesquisa, o envolvimento dos estudantes nas atividades de produção (escrita, matemática); a criatividade; a curiosidade; e, principalmente, a capacidade de contextualização dos conhecimentos construídos no decorrer da oficina com a realidade do meio no qual se encontram inseridos, estreitando relações do abstrato/imaginário com o concreto/real.

Desta forma, os resultados de aprendizagem constituíram-se em produções contextualizadas com o meio em que as instituições escolares estão inseridas. Muitas delas também se demonstraram criativas ao reproduzir cenários imaginários. Considera-se que, ao aliar a Literatura às aulas de Matemática, criou-se um ambiente de aprendizado mais eficiente, duradouro e criativo. Além disso, os conteúdos matemáticos explorados através do embasamento literário e desenvolvidos em atividades lúdicas, sem a imposição de ideias, priorizando ao estudante oportunidade de criar, reinventar e formular hipóteses de soluções, tornaram significativa e completa a aprendizagem.

As análises ainda indicam que a aplicação da Literatura nas aulas de Matemática surge como uma alternativa para disseminar concepções inovadoras sobre o ensino, além de contribuir para a reflexão de que os saberes são acessíveis a todos, tornando concreto e investigativo o processo de ensino aprendizagem da Matemática. Portanto, expõe-se o ponto de partida para o conhecimento, mas, não se impõem limites, ou seja, não se sabe o ponto de chegada, sujeito às peculiaridades de cada mente criativa e às possibilidades que o contexto oferece. 


\section{Referências}

BRASIL. Ministério da Educação. Secretaria de Ensino Fundamental. Parâmetros Curriculares Nacionais. Brasília: MEC/SEF, 1997.

KOSMINSKI, Edson L. As Três Partes. 12. ed. São Paulo: Ática, 2009. 24 p. (Histórias de Contar).

SALVADOR, Teresinha M.; SILVA, Marines F.; ZINI, Adriana. Literatura infantil nas aulas de matemática e ciências. 2007. Disponível em: $<$ http://www.caxias.rs.gov.br/geemac/_upload/encontro_46.pdf $>$. Acesso em: 30 nov. 2010.

SMOLE, Kátia C. S.; CÂNDIDO, Patrícia T.; STANCANELLI, Renata. Matemática e literatura infantil. 4 ed. Belo Horizonte: Lê, 1999. 134 p.

SMOLE, Kátia C. S.; ROCHA, Glauce H. R.; CÂNDIDO, Patrícia T.; STANCANELLI, Renata. Era uma vez na matemática: uma conexão com a literatura infantil. 6. ed. São Paulo: IME -USP, 2007. 99 p. 